\title{
A TONIC $\gamma$-AMINOBUTYRIC ACID-MEDIATED INHIBITION OF CHOLINERGIC AMACRINE CELLS IN RABBIT RETINA ${ }^{1}$
}

\author{
STEPHEN C. MASSEY ${ }^{2}$ AND DIANNA A. REDBURN
}

Department of Neurobiology and Analomy, University of Texas Medical School at Houston, Houston, Texas 77025

Received March 8, 1982; Revised May 19, 1982; Accepted May 21, 1982

\begin{abstract}
Using the in vivo rabbit eyecup, we have studied the light-evoked release of acetylcholine (ACh) which is presumed to indicate the activity of cholinergic amacrine cells. $\gamma$-Aminobutyric acid (GABA) inhibited the light-evoked release of $\mathrm{ACh}\left(\mathrm{IC}_{50} \simeq 1 \mathrm{~mm}\right)$, but the GABA antagonists bicuculline $(5 \mu \mathrm{M})$ and picrotoxin $(20 \mu \mathrm{M})$ potentiated the light-evoked release and markedly increased the resting release of ACh. This bicuculline/picrotoxin-evoked release was calcium dependent and the effects of bicuculline, but not picrotoxin, were blocked by muscimol, a potent GABA agonist. Muscimol also inhibited the light-evoked release of $\mathrm{ACh}\left(\mathrm{IC}_{50}<1 \mu \mathrm{M}\right)$ and was at least 1000 times more potent than GABA. Nipecotic acid ( $1 \mathrm{mM}$ ), a GABA transport blocker, also inhibited the light-evoked release of $\mathrm{ACh}$, but the effect was slow in onset and recovery was prompt.

We conclude that the cholinergic amacrine cells of rabbit retina are inhibited by GABA. The relatively weak action of GABA, compared to muscimol, may be due to the presence of avid GABA transport systems. We ascribe the excitatory effects of hicuculline and picrotoxin to the antagonism of endogenous GABA, suggesting that the cholinergic cells are influenced by a tonic release of GABA. This is consistent with the effects of nipecotic acid. Although we are unable to specify the synaptic arrangements involved, we suggest that the most likely interaction is directly between GABA amacrine cells and the cholinergic amacrine cells and/or their presumed bipolar cell inputs.
\end{abstract}

There is compelling evidence for cholinergic transmission in the vertebrate retina. The cholinergic markers choline acetyltransferase (CAT; EC 2.3.1.6) (Ross and McDougall, 1976) and acetylcholinesterase (AChE; EC 3.1.1.7) (Nichols and Koelle, 1968), $\alpha$-bungarotoxin $(\alpha-$ BTX) binding sites (Vogel et al., 1977; Pourcho, 1979; Daniels and Vogel, 1980), muscarinic binding sites (Sugiyama et al., 1977), and high affinity choline (Ch) uptake (Baughman and Bader, 1977; Masland and Mills, 1979) are all present and are localized predominantly to the proximal layers of the retina. In addition, ganglion cells are responsive to the application of cholinergic drugs (Masland and Ames, 1976; Negishi et al., 1978; Ariel and Daw, 1978, 1979) and acetylcholine (ACh) may be released by flashing light (Masland and Livingstone, 1976; Massey and Neal, 1979; Neal and Massey, 1980; Vivas

\footnotetext{
' This work was supported by National Eye Institute Grants RO1EY0-1655, RCDA-1K04-00088, and EYO-7024-06. We wish to thank Dr. John Haycock for advice, Dr. Robert Marc for critical comments on the first draft of the manuscript and Ms. Diana Parker for secretarial assistance.

${ }^{2}$ To whom correspondence should be addressed at his current address: Department of Ophthalmology, Washington University School of Medicine, St. Louis, MO 63110.
}

and Drujan, 1980). In summary, these studies implicate some amacrine and bipolar cells as the most likely candidates for the cholinergic neurons of the vertebrate retina.

Using $\left[{ }^{3} \mathrm{H}\right] \mathrm{Ch}$ and a process of dry autoradiography combined with "ACh-protecting" conditions, Masland and Mills (1979) identified the cholinergic neurons of the rabbit retina as two cell populations sparsely bordering the inner plexiform layer in a symmetrical fashion with terminals ramifying in sublaminas 2 and 4 . These cells probably correspond to the monostratified matching populations stained by Vaney et al. (1981) using neurofibrillar methods. The more distal neurons fit the classical description of amacrine cells, while those in the ganglion cell layer were identified as displaced amacrine cells on the basis of double label experiments. True ganglion cells did not accumulate $\left[{ }^{3} \mathrm{H}\right] \mathrm{Ch}$ and could be depleted by sectioning the optic nerve or stained with a fluorescent dye applied to the optic nerve stump (Hayden et al., 1980). Displaced amacrine cells recently have been identified in numbers sufficient to accommodate the cholinergic neurons in the ganglion cell layer (Ehrlich and Morgan, 1980; Hughes and Vaney, 1980; Vaney, 1980), which may account for a large fraction of this cell type.

In addition to the amacrine cell types described in the 
rabbit retina, Baughman and Bader (1977) found cholineaccumulating somas deep in the inner nuclear layer of the chicken retina, suggesting the presence of cholinergic bipolar cells. This idea is supported by the postsynaptic localization of $\alpha$-BTX/horseradish peroxidase ( $\alpha$-BTX/ HRP) at both conventional and ribbon synapses in the chicken retina (Vogel et al., 1977; Daniels and Vogel, 1980). These results indicate some species variation since $\alpha$-BTX/HRP was restricted to conventional synapses in the mouse retina (Pourcho, 1979). If indeed the chicken retina does possess cholinergic bipolar cells, this is not the case in the rabbit retina since the cholinergic cells of the inner nuclear layer were, without exception, located immediately adjacent to the inner plexiform layer (Masland and Mills, 1979).

Although the cholinergic markers are concentrated in the inner retina, they are not confined exclusively to this area; there are traces of AChE (Reale et al., 1971) and some $\alpha$-BTX binding (Vogel and Nirenberg, 1976) in the outer plexiform layer of the rabbit retina, which might suggest the possibility of cholinergic photoreceptors. However, the significance of these results is not clcar since AChE is not a reliable marker for ACh (Silver, 1974; Lehman and Fibiger, 1979) and it appears to be located in glial cells of goldfish and turtle retinas (Nicholas et al., 1972; Sarthy and Lam, 1978). Furthermore, it is not clear whether $\alpha$-BTX labels only synaptic receptors (Zucker and Yazulla, 1982). Electrophysiological results from horizontal cells in response to cholinergic drugs have been variable. Positive results in the mud puppy (Belgum and McReynolds, 1979) and turtle (Gerschenfeld and Piccolino, 1977), albeit with high drug concentrations, are supported by evidence that mud puppy photoreceptors contain some CAT (Graham, 1974) and turtle photoreceptors can synthesize trace amounts of ACh (Lam, 1972; Graham, 1974; Sarthy and Lam, 1978). However, similar experiments on horizontal cells of cat and fish retinas have been either negative (Murakami et al., 1972; Niemeyer, 1978; Wu and Dowling, 1978) or the cholinergic effects originated in the inner plexiform layer and were mediated through interplexiform cells (Kaneko and Shimazaki, 1976; Negishi and Drujan, 1979).

Thus, while it seems possible that some species have cholinergic photoreceptors, their numbers must be extremely limited in the rabbit since the CAT activity of the distal retina was less than $1 \%$ of that in the inner retina (Ross and McDougall, 1976). Furthermore, Masland and Mills (1979) showed that $96 \%$ of the $\left[{ }^{3} \mathrm{H}\right] \mathrm{ACh}$ synthesis occurred in the inner layers of the rabbit retina. In view of this evidence, with the consideration that photoreceptors would be expected to decrease transmitter release in response to light, it seems clear that the light-evoked release of $\mathrm{ACh}$ from the rabbit retina originates predominantly, if not exclusively, from cholinergic amacrine and displaced amacrine cells and we shall proceed on this basis.

The release of $\mathrm{ACh}$ in response to the appropriate physiological stimulus represents a method of monitoring the activity of the cholinergic amacrine cells and of identifying the synaptic mechanisms controlling them. Following this strategy, it was shown previously that $\gamma$ aminobutyric acid (GABA) inhibits the light-evoked release of $\left[{ }^{3} \mathrm{H}\right] \mathrm{ACh}$ from the rabbit retina (Massey and Neal, 1979; Neal and Massey, 1980). This interaction is entirely consistent with the proposed identity of the cholinergic cells since GABA and its synthesizing enzyme, glutamic acid decarboxylase, appear to be restricted to the inner layers of the rabbit retina (Ehinger and Falck, 1971; Brandon et al., 1979, 1980; Lam et al., 1980 ), although in other, nonmammalian retinas, GABA also may be a horizontal cell transmitter (Lam et al., 1978, 1979; Marc et al., 1978).

In the experiments reported herein, we have confirmed and extended the earlier results using a variety of GABA analogues and we have attempted to establish the specificity of the GABA antagonists employed. The actions of these agents have several implications for the inhibitory circuits of the retina.

\section{Materials and Methods}

New Zealand White rabbits of either sex (1.5. to 2.5 $\mathrm{kg})$ were anesthetized with urethane $(\simeq 1.5 \mathrm{gm} / \mathrm{kg}$, i.p. $)$ and a tracheal cannula was inserted to ensure a clear airway. Body temperature was maintained at $37^{\circ} \mathrm{C}$ by a thermostatically controlled heated blanket and was monitored with a rectal probe. The head was turned sideways and clamped and the upper eye was proptosed with the aid of a hemostat. Using a curved atraumatic suture (Ethicon taper RB-1), a stainless steel support ring was sutured to the eye at the sclerocorneal junction. The eye was opened with a scalpel anterior to the supporting ring and the cornea and iris were cut away with fine curved scissors. Bleeding was arrested by cauterization when necessary.

The lens was removed and the vitreous humor was extracted using tissue swabs and blunt curved forceps. This often proved difficult, but, when successful, the vitreous invariably came out as a large globule. This usually indicated complete removal. The integrity of the retina is important, particularly since a damaged retina will detach during prolonged superfusion; consequently, the resulting eyecup was flushed with Krebs solution and the retina was examined closely for tears, detachment, or bleeding.

Low impedance $\mathrm{Ag} / \mathrm{AgCl}$ electrodes were used to record the electroretinogram (ERG); a normal ERG indicated that the retina was electrophysiologically functional at the beginning of the experiment. The ERG normally was monitored throughout each experiment and proved especially useful for identifying a detached retina quickly.

To label retinal ACh, a $20-\mu \mathrm{Ci}$ aliquot of an ethanolic solution of $\left[{ }^{3} \mathrm{H}\right] \mathrm{Ch}(80 \mu \mathrm{Ci} / \mathrm{mmol}$, New England Nuclear) was evaporated to dryness in a stream of air, redissolved in a small volume of Krebs solution, and added to the eyecup. The incubation period was $30 \mathrm{~min}$, and during this time, the retina was stimulated at $3 \mathrm{~Hz}$ to maximize choline uptake (Masland and Livingstone, 1976). The eyecup then was emptied carefully and flushed several times with Krebs solution using a Pasteur pipette before the superfusion cannulae were lowered into place. Background radioactivity was reduced by washing the preparation for $60 \mathrm{~min}$ via the perfusion system with Krebs solution containing $30 \mu \mathrm{m}$ eserine sulfate. During this 
time, the retina was left to dark-adapt and the rest of the experiment was conducted under dim red light.

The superfusion system, constructed from fine gauge polyethylene tubing (Intramedic PE-50) to minimize the dead space, was driven at $1.5 \mathrm{ml} / \mathrm{min}$ by a peristaltic pump (Harvard). This gave a conveniently short lag time for both inflow (10 sec) and outflow (12 sec), and the eyecup contents (approximately $500 \mu \mathrm{l}$ ) were replaced five or six times in every 2 -min collection period. The cannulae were constructed from 24 gauge stainless steel tubing and the inflow cannula was twisted slightly to cause some turbulence. Raising the position of the outflow relative to the inflow gave the desired depth of fluid in the eyecup and a constant level was maintained by running the outflow channel slightly faster than the inflow (Fig. 1). Preliminary dye studies showed that thorough mixing took place with this arrangement. Samples were collected directly into scintillation vials and the resulting 3-ml fractions were prepared for counting by the addition of $10 \mathrm{ml}$ of modified Tritosol counting solution (Pande, 1976).

Light stimulation ( $3 \mathrm{~Hz}, 4 \mathrm{~min}$ ) was produced by a xenon photic stimulator (Grass PS 22, setting A) which provided a brightly photopic flash of $10 \mu$ sec duration. Stimulation was started $12 \mathrm{sec}$ before the fraction collector (ISCO 328) to allow for the dead time on the outflow. Drugs were applied to the retina by changing the reservoir to one containing the required drug at an appropriate concentration. Precautions were taken to prevent contamination, and after each experiment, the system was flushed with distilled water.
The composition of the Krebs bicarbonate medium used throughout these experiments consisted of $\mathrm{NaCl}$, $118 \mathrm{~mm} ; \mathrm{NaHCO}_{3}, 25 \mathrm{~mm} ; \mathrm{KCl}, 4.7 \mathrm{~mm} ; \mathrm{CaCl}_{2}, 2.5 \mathrm{~mm}$; $\mathrm{MgSO}_{4}, 1.2 \mathrm{~mm} ; \mathrm{KH}_{2} \mathrm{PO}_{4}, 1.2 \mathrm{~mm}$; glucose, $11.1 \mathrm{~mm}$, freshly prepared and gassed with $95 \% \mathrm{O}_{2}, 5 \% \mathrm{CO}_{2}$ to $\mathrm{pH}$ 7.4. Low $\mathrm{Ca}^{2+}$, high $\mathrm{Mg}^{2+}$ medium was identical, except the $\mathrm{CaCl}_{2}$ concentration was $0.25 \mathrm{mM}$ and $20 \mathrm{~mm}$ excess $\mathrm{MgSO}_{4}$ was added. Eserine sulfate $(30 \mu \mathrm{M})$ was present at all times except for the loading period. All chemicals were obtained from commercial sources except for muscimol and nipecotic acid which were gifts from Dr. S. J. Enna (Department of Neurobiology and Anatomy, University of Texas Medical School at Houston) and TAG which was a gift from Dr. G. Yarbrough (Merck Sharp and Dohme Research Laboratories, West Point, PA). All drugs were dissolved directly into the Krebs solution except for bicuculline hydrochloride for which a stock solution was prepared in $0.1 \mathrm{~N} \mathrm{HCl}$ for dilution in Krebs solution shortly before use (Olsen et al., 1975).

In some experiments, $\left[{ }^{3} \mathrm{H}\right] \mathrm{ACh}$ was separated from $\left[{ }^{3} \mathrm{H}\right] \mathrm{Ch}$ by the enzymatic method of Shea and Aprison (1973) as adapted by Johnson and Pilar (1980), with minor modifications. Briefly, 1-ml aliquots were taken from each release fraction, acidified with $20 \mu \mathrm{l}$ of $1 \mathrm{~N} \mathrm{HCl}$, and frozen. Two stock solutions were prepared: (1) 100 $\mathrm{mM} \mathrm{MgCl}, 100 \mathrm{~mm}$ ATP, and $10 \mathrm{~mm}$ dithiothreitol in 0.3 $\mathrm{N}$ Tris base and (2) choline kinase (Sigma C-7138), 0.1 unit/ml in Tris ( $\mathrm{pH} 7.2$ ). At a convenient time, the samples were thawed and choline was phosphorylated by the addition of $100 \mu \mathrm{l}$ from each stock with incubation at $37^{\circ} \mathrm{C}$ for $10 \mathrm{~min}$. The final $\mathrm{pH}$ of the reaction mixture

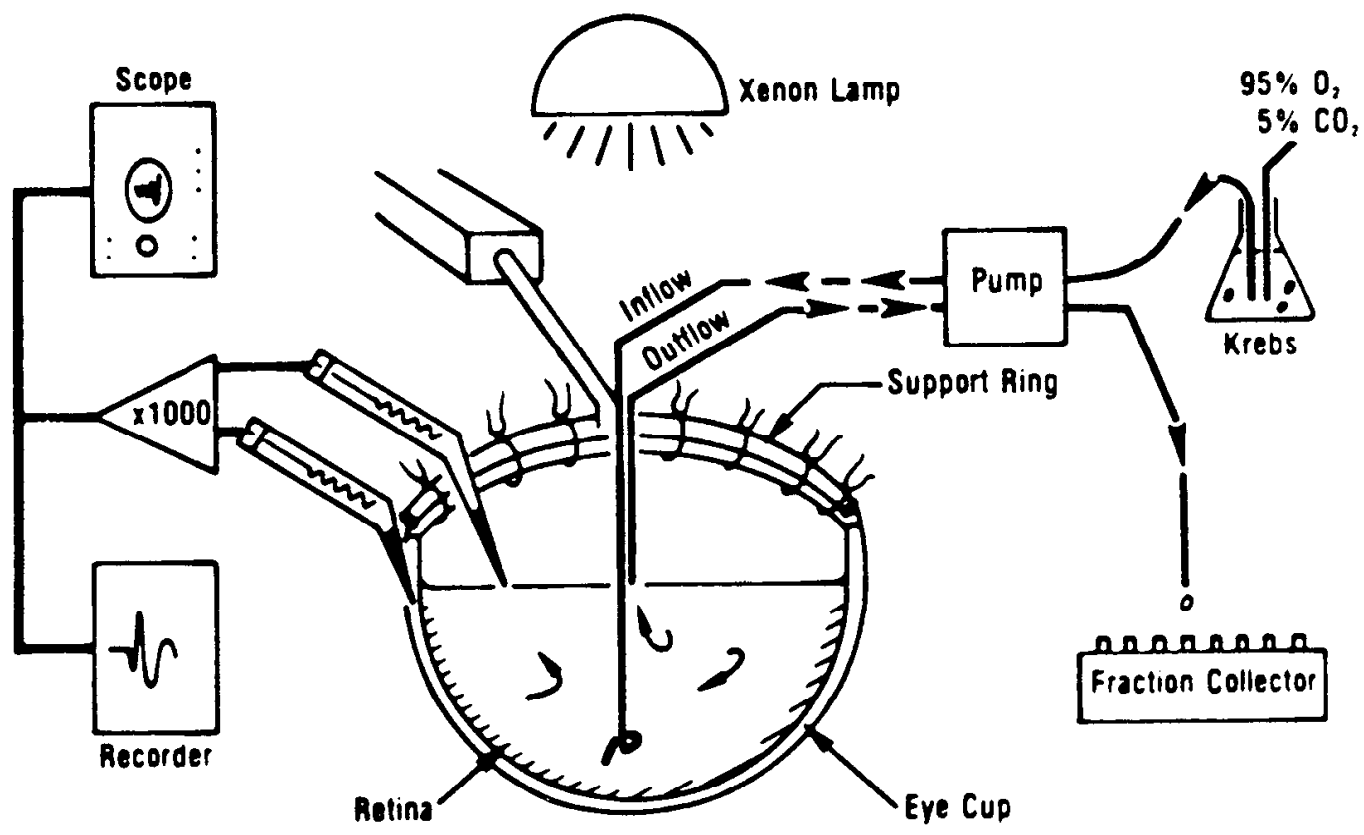

Figure 1. A diagrammatic illustration of the rabbit eyecup preparation. After the contents of the eye were removed, the retina was loaded with $\left[{ }^{3} \mathrm{H}\right] \mathrm{Ch}(20 \mu \mathrm{Ci})$ for $30 \mathrm{~min}$ with light stimulation at $3 \mathrm{~Hz}$. The preparation was allowed to dark-adapt for $60 \mathrm{~min}$ during the washout phase and then fractions were collected at 2-min intervals. Light stimulation $(4 \mathrm{~min}, 3 \mathrm{~Hz}$ ) was provided by a Grass PS 22 photic stimulator (setting A). The ERG could be recorded via low impedance electrodes; a normal ERG showed that the preparation was electrophysiologically functional at the beginning of the experiment. 
was 8.6. The reaction was stopped by the addition of 4 $\mathrm{ml}$ of ice cold $0.1 \mathrm{~N}$ Tris- $\mathrm{HCl}$ and ACh was extracted by shaking with $2 \mathrm{ml}$ of tetraphenylboron in acetonitrile (10 $\mathrm{mg} / \mathrm{ml}$ ) (Fonnum, 1969). Ten milliliters of a toluenebased fluor were added directly to each vial and radioactivity was estimated in a Searle Mark III liquid scintillation counter. The crossover from $\mathrm{Ch}$ to $\mathrm{ACh}$ was approximately $7 \%$ for which a correction was applied.

\section{Results}

Light stimulation at $3 \mathrm{~Hz}$ caused a prompt rise in the efflux of total radioactivity from the rabbit eyecup (evoked release/resting release $(E / R)=5.5$ ). Analysis of the perfusate revealed that essentially all of the lightevoked release was due to an increase in the efflux of $\left[{ }^{3} \mathrm{H}\right] \mathrm{ACh}(E / R=11.0$; Fig. 2$)$. The release of $\left[{ }^{3} \mathrm{H}\right] \mathrm{Ch}$ (estimated by subtraction of $\left[{ }^{3} \mathrm{H}\right] \mathrm{ACh}$ from total radioactivity) accounted for roughly half of the basal efflux but was unchanged by light stimulation (Fig. 2). These results are in close agreement with previous work using this preparation when $\mathrm{ACh}$ and $\mathrm{Ch}$ were separated by high voltage paper electrophoresis (Massey and Neal, 1979). However, with the rapid perfusion system, we note that ACh accounts for more of the basal efflux $(50 \%$ versus $20 \%$ ) and the light-evoked release of ACh is much greater ( $E / R$ of 11 versus 4.1 ) than in the previous report when there was no superfusion and the stationary contents of the eyecup were removed at 10-min intervals. We surmise that continuous perfusion may improve the condition of the retina or, alternatively, the rapid removal of released ACh may prevent some form of feedback inhibition. This latter suggestion is consistent with the effect of atropine which potentiates the release of ACh from the rabbit retina and other cholinergic systems (Hadhazy and Szerb, 1977; Massey and Redburn, 1980).

In view of the above results, the perfusate analysis was not carried out in most experiments, but, rather, increments in the efflux of total radioactivity were taken to be indicative of $\mathrm{ACh}$ release which was quantified by the integration of the light-evoked peaks. However, it is important to note that the $E / R$ values for ACh may be approximately double those shown for total radioactivity.

Exposure of the retina to GABA (1 mM) caused a marked depression in the light-evoked release of $\mathrm{ACh}$ (Fig. 3) with a small, but reproducible, drop in the resting release rate. This was accompanied by an increase in the amplitude of the B wave of the ERG as also reported by Starr (1975). The GABA antagonists bicuculline (5 $\mu \mathrm{M})$ and picrotoxin $(20 \mu \mathrm{M})$ caused a striking increase in the resting release rate of $\mathrm{ACh}$, but the efflux of $\left[{ }^{3} \mathrm{H}\right] \mathrm{Ch}$ was not affecled: light stimulation in the presence of either GABA antagonist caused a further large increase in $\mathrm{ACh}$ release. Picrotoxin also depressed the $B$ wave, but, paradoxically, bicuculline did not alter the ERG, possibly reflecting some difference in their mechanism of action. In contrast to the GABA antagonists, $5 \mu \mathrm{M}$ strychnine had no effect on the resting or light-evoked release of ACh. Under these conditions, the cholinergic neurons do not appear to receive an inhibitory glycinergic input.

If the increased $\mathrm{ACh}$ release produced by bicuculline in the absence of light stimulation results from neuronal stimulus-secretion coupling, it also should be $\mathrm{Ca}^{2+} \mathrm{de}-$ pendent; Figure 4 shows that this criterion is satisfied.
A

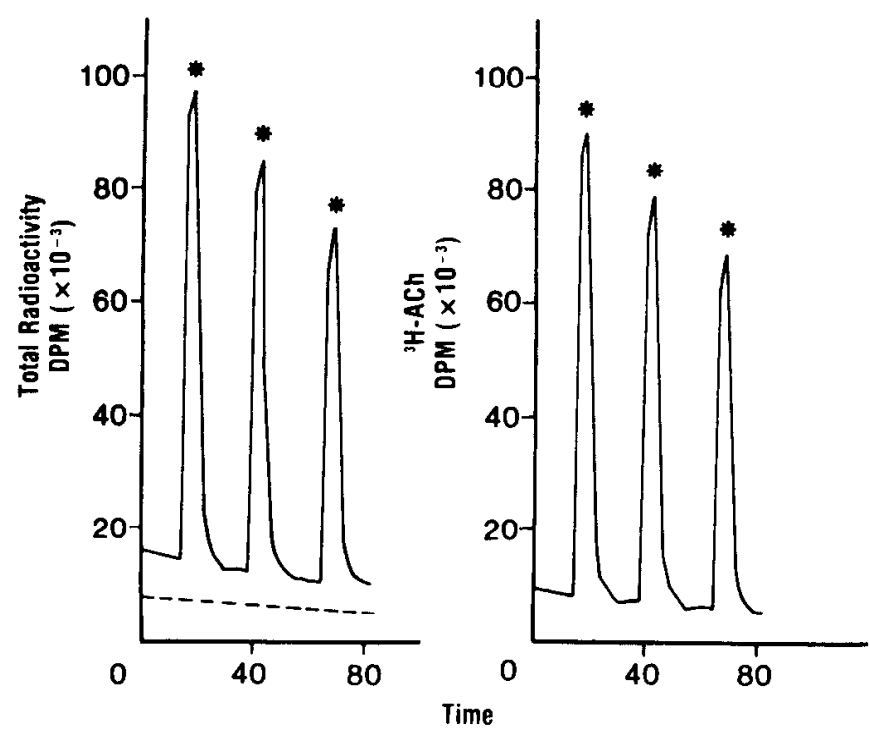

C

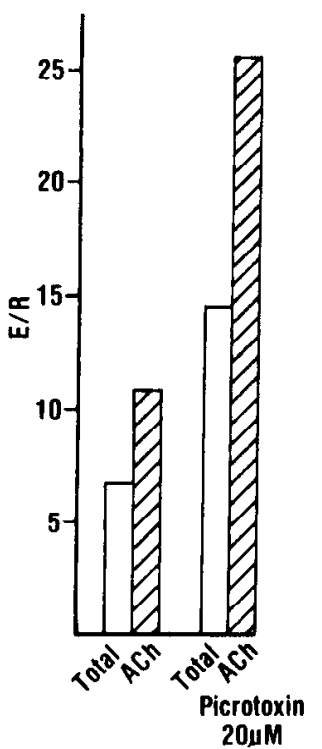

Figure 2. Analysis of the light-evoked release of radioactivity from the rabbit retina. The asterisks indicate light stimulation at $3 \mathrm{~Hz}$ for $4 \mathrm{~min}$. $A$, A portion of each sample was counted directly, giving the light-evoked release of total radioactivity (Ch and $\mathrm{ACh})$. The dashed line is an estimate of $\left[{ }^{3} \mathrm{H}\right] \mathrm{Ch}$ release obtained by subtracting $\left[{ }^{3} \mathrm{H}\right] \mathrm{ACh}$ release from the total (i.e., $A-B$ ). The release of $\mathrm{Ch}$ was not influenced by light. $B$, The light-evoked release of $\left[{ }^{3} \mathrm{H}\right] \mathrm{ACh}$ from the rabbit retina obtained after an enzyme-based separation of $\mathrm{Ch}$ and $\mathrm{ACh}$ (see text). A comparison of $A$ and $B$ indicates that essentially all of the light-evoked release consists of ACh. $C$, Light-evoked/resting release ratio $(E / R)$ for total radioactivity and $\left[{ }^{3} \mathrm{H}\right] \mathrm{ACh}$ under normal conditions and in the presence of picrotoxin. Each bar is the mean of four experiments; standard errors were less than $12 \%$. 


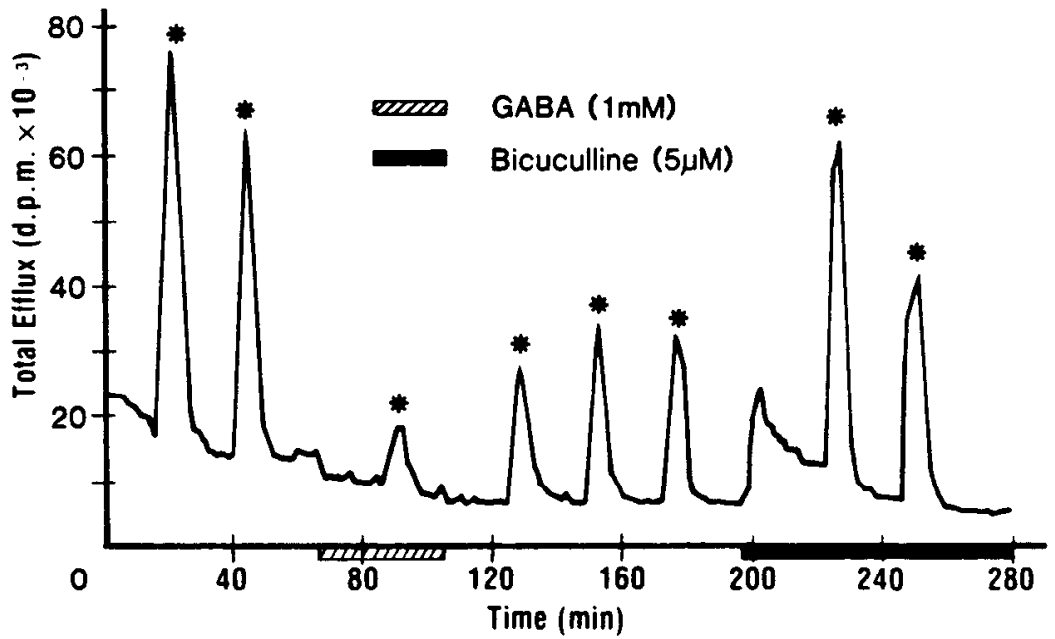

Figure 3. The effect of GABA $(1 \mathrm{mM})$ and bicuculline $(5 \mu \mathrm{M})$ on the light-evoked release of ACh. The asterisks indicate light stimulation for $4 \mathrm{~min}$ at $3 \mathrm{~Hz}$. The light-evoked release of ACh was inhibited by GABA but clearly enhanced by bicuculline. A similar result was seen when bicuculline was replaced with picrotoxin $(20 \mu \mathrm{M})$. The peak immediately after the addition of bicuculline represents a change in the spontaneous release which we ascribe to GABA disinhibition.

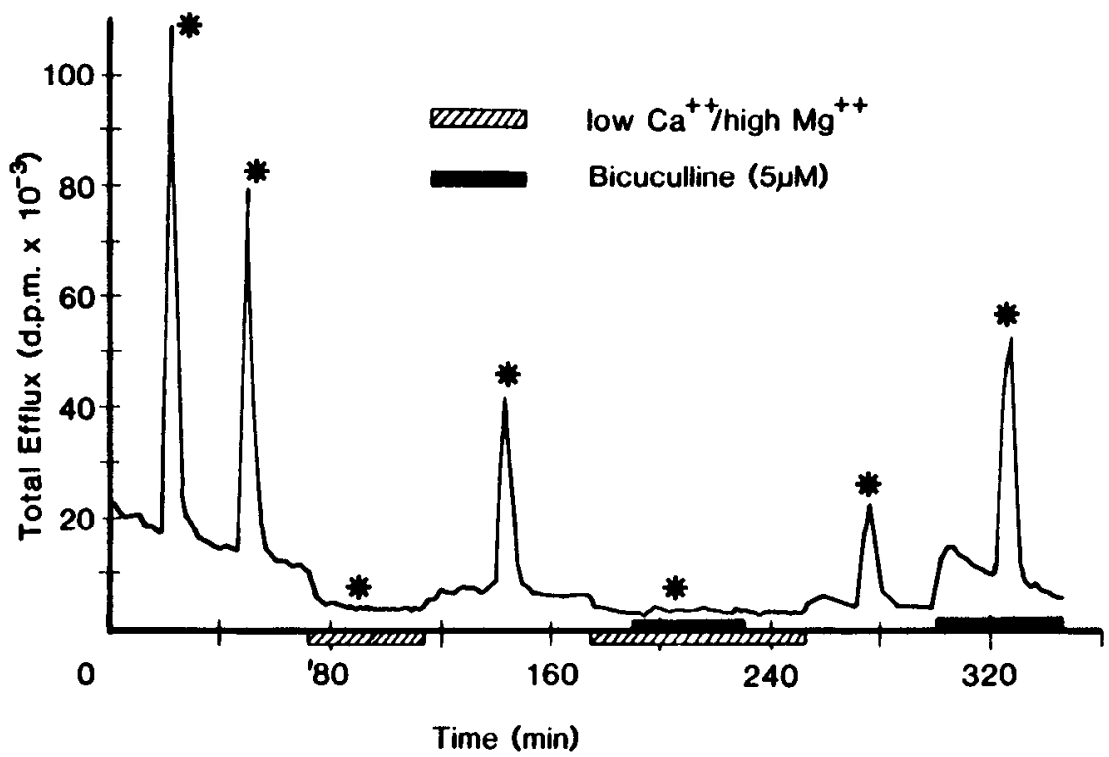

Figure 4. The bicuculline-evoked release of $\mathrm{ACh}$ is calcium dependent. The asterisks indicate light stimulation for 4 min at 3 $\mathrm{Hz}$. The first half of the figure shows that, in low $\mathrm{Ca}^{2+} /$ high $\mathrm{Mg}^{2+} \mathrm{Krebs}$ solution, the resting release fell by approximately $50 \%$ and the light-evoked release of ACh was abolished. On return to normal Krebs solution, a control response was obtained. When $5 \mu \mathrm{M}$ bicuculline was applied during perfusion with low $\mathrm{Ca}^{21} / \mathrm{high} \mathrm{Mg}^{2}$ Krebs solution, there was no change in basal efflux even with light stimulation. On return to normal Krebs solution, another control response was obtained and then bicuculline caused a large increase in the resting release rate and clearly potentiated the light-evoked response. A similar result was seen when bicuculline was replaced with picrotoxin $(20 \mu \mathrm{M})$.

The effects of both bicuculline and light stimulation were abolished during perfusion with low $\mathrm{Ca}^{2+} /$ high $\mathrm{Mg}^{2+}$ Krebs solution. However, on return to normal medium, the usual effects of light stimulation and bicuculline were observed on spontaneous and light-evoked release.

We also examined the effects of the GABA agonist muscimol. 'This drug was extremely effective (approximately 2000 times more potent than GABA) and caused a $90 \%$ inhibition of light-evoked ACh release at a concentration of $1 \mu \mathrm{M}$ (Fig. 5). This action was reversible, although recovery was prolonged. In contrast to GABA, muscimol had little effect on the ERG. Muscimol also caused a substantial drop in the basal efflux of radioactivity which perfusate analysis showed was due to the abolition of resting ACh release. In agreement with our estimate from Figure 2 and the effect of low $\mathrm{Ca}^{2+} / \mathrm{high}$ $\mathrm{Mg}^{2+}$ Krebs solution, this shows that approximately $50 \%$ of the resting release of total radioactivity is due to $\mathrm{ACh}$.

The potency of muscimol suggested a way to test the pharmacological specificity of the GABA antagonists. Therefore, bicuculline and picrotoxin were applied to the eyecup in 4-min pulses in the presence of muscimol (2 or $5 \mu \mathrm{M}$ ) (Fig. 6). The bicuculline-evoked release of ACh was blocked by muscimol, but picrotoxin was still effective 


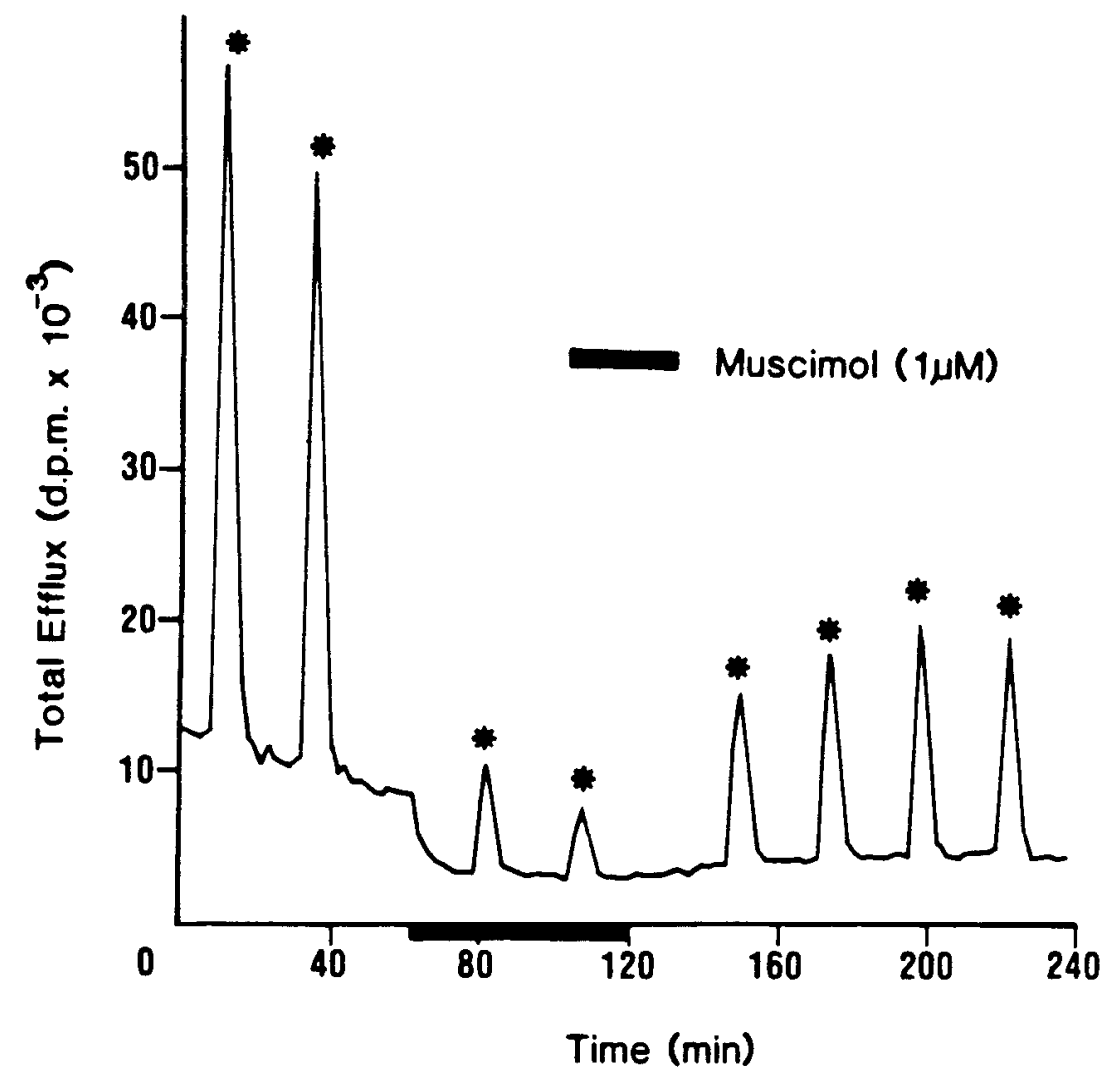

Figure 5. The effect of muscimol on the light-evoked release of ACh. The asterisks indicate light stimulation for $4 \mathrm{~min}$ at $3 \mathrm{~Hz}$. Muscimol $(1 \mu \mathrm{M})$ caused a $50 \%$ drop in the resting release rate and strongly inhibited the light-evoked release of $\mathrm{ACh}$; recovery was prolonged.

when applied at a concentration of $20 \mu \mathrm{M}$ which was shown to be submaximal (Fig. 6). This result suggests a common site of action for bicuculline and muscimol but a separate site for picrotoxin. Recovery of the lightevoked release was prolonged due to the higher concentration of muscimol, but this was reversed rapidly on control application of bicuculline which elicited the normal response.

We postulated that the relatively high dose of GABA required to inhibit $\mathrm{ACh}$ release, when compared to the efficacy of muscimol, might be explained by the presence of neuronal and glial GABA uptake systems which would decrease the local concentration of GABA but only transport muscimol poorly. Nipecotic acid (1 mM), a substance known to block GABA transport without activating the GABA receptor, inhibited the light-evoked release of ACh (Fig. 7) and decreased the basal efflux in a way similar to the depression seen with GABA or muscimol. However, close examination reveals several differences: (1) inhibition of light-evoked release was slow in onset; (2) the decline in basal efflux was gradual, especially compared with the rapid drop seen with muscimol; and (3) the recovery was rapid. We suggest these effects may be attributed to the slow accumulation of extracellular GABA caused by a block of GABA transport. Furthermore, and in contrast to muscimol, nipecotic acid also mimics the effect of GABA on the ERG but, again, with a slow onset and rapid recovery consistent with the above interpretation.

\section{Discussion}

Our major findings may be summarized as follows.

(1) These experiments clearly demonstrate a GABAmediated inhibition of the cholinergic neurons in the rabbit inner retina. However, we are unable to specify the underlying connections by this technique since we have no evidence that GABA impinges directly on the cholinergic amacrine cells, although this would provide a simple explanation for our observations.

(2) GABA uptake systems may play an important role in retinal function based on the observations that: $(a)$ the extreme potency of muscimol, as compared to GABA, appears to be due, at least in part, to its relatively poor affinity for the GABA transport site and $(b)$ nipecotic acid alone produced a gradual inhibition of ACh release.

(3) The stimulation of basal efflux elicited by bicuculline and picrotoxin, which we ascribe to GABA disinhibition, indicates that the cholinergic amacrine cells receive a continuous or tonic GABA input. We stress, however, that these interpretations are critically dependent on the pharmacological specificity of the compounds employed, which merits careful consideration.

Specificity of GABA-mimetic drugs. By the criteria of neuronal inhibition (Krogsgaard-Larsen et al., 1978) or 


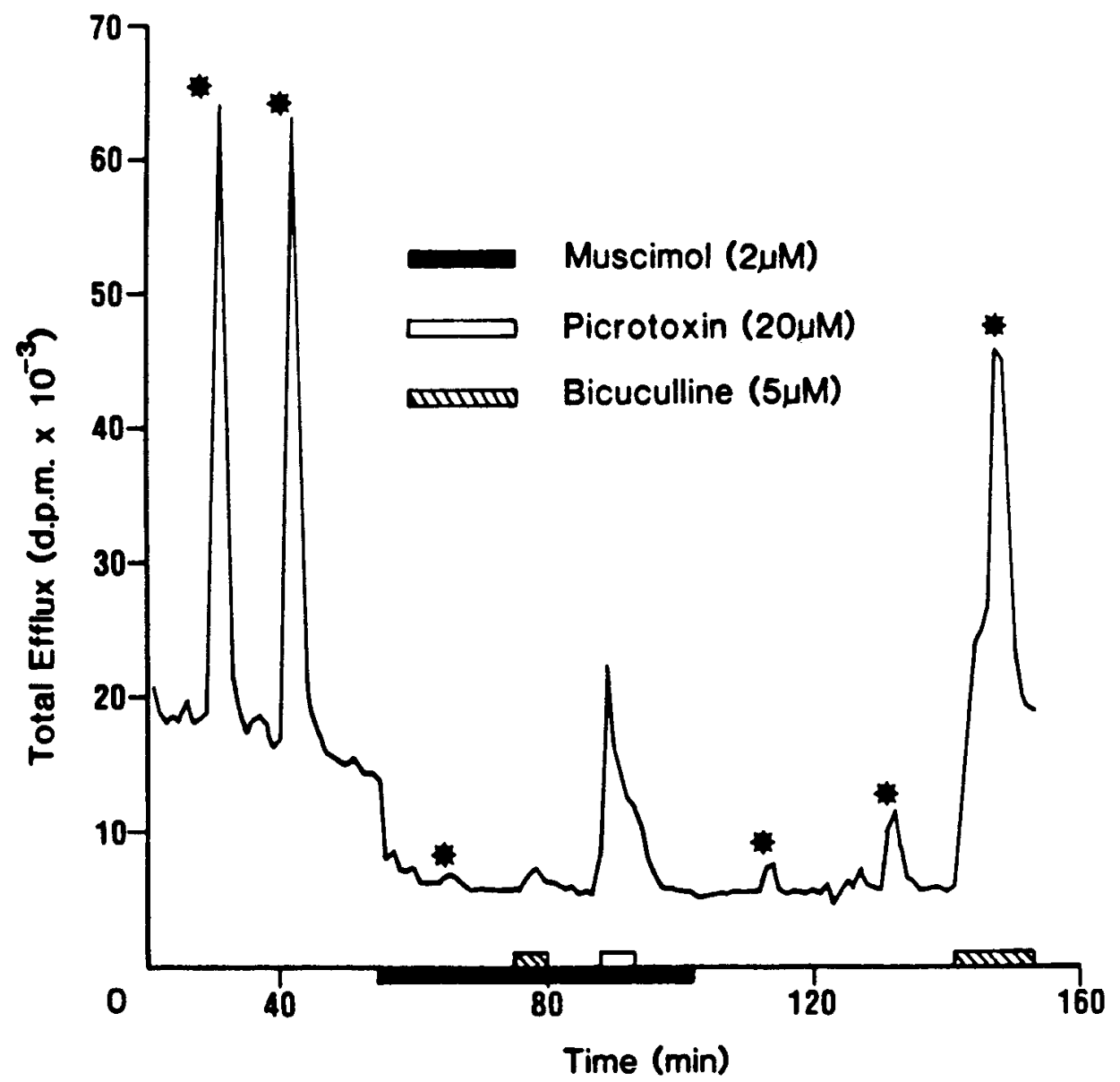

Figure 6. Muscimol blocks the effects of bicuculline but not picrotoxin. The asterisks indicate light stimulation for $4 \mathrm{~min}$ at $3 \mathrm{~Hz}$. Muscimol $(2 \mu \mathrm{M})$ caused a pronounced drop in the basal efflux and almost abolished the light-evoked release of ACh. During the muscimol perfusion, a 4-min pulse of bicuculline $(5 \mu \mathrm{M})$ had practically no effect, but a 4-min pulse of picrotoxin $(20 \mu \mathrm{M})$ caused a large increase in release rate. After removing the muscimol, the light-evoked responses were small and recovery was slow. A control application of bicuculline caused the normal large increase in resting release and strongly potentiated the light-evoked release of ACh. This experiment shows that muscimol can be used to differentiate between bicuculline and picrotoxin.

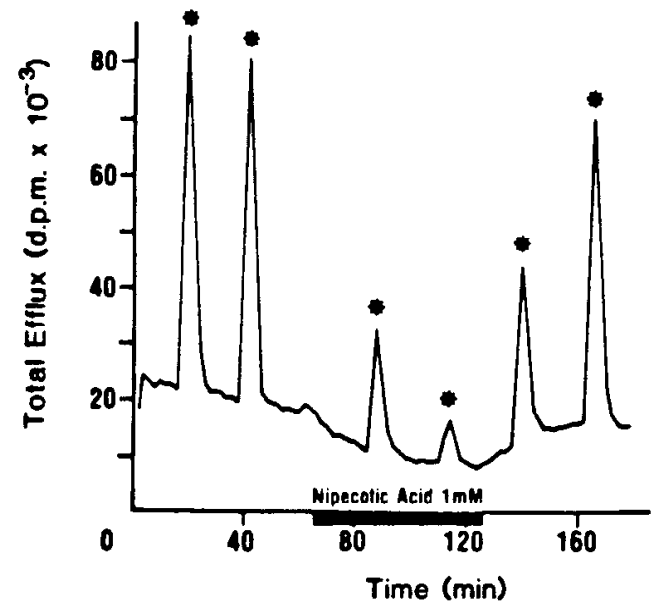

Figure 7. The effect of nipecotic acid on the light-evoked release of $\mathrm{ACh}$. The asterisks indicate light stimulation for 4 min at $3 \mathrm{~Hz}$. Nipecotic acid ( $1 \mathrm{~mm}$ ) caused a slow depression in basal efflux and inhibited the light-evoked release of $\mathrm{ACh}$. In contrast to GABA or muscimol, the recovery on washout was prompt. ligand binding studies with GABA and bicuculline (Johnston, 1978), the isoxazole, muscimol, is a potent and specific GABA agonist at bicuculline-sensitive, strychnine-insensitive receptors, although there may be some additional binding sites (DeFeudis, 1980). It is a weak inhibitor of GABA uptake (Johnston et al., 1978) and is poorly accumulated by neurons in the retina (Yazulla and Brecha, 1980; Pourcho, 1981). Muscimol $\left(\mathrm{IC}_{50}<1\right.$ $\mu \mathrm{M})$ is at least 1000 times more potent than GABA $\left(\mathrm{IC}_{50}\right.$ $\simeq 1 \mathrm{mM}$ ) for the inhibition of light-evoked ACh release, which is in marked contrast to the dose ratio of approximately 5 reported for the depression of cortical neurons (Krogsgaard-Larsen et al., 1977) or displacement of receptor binding in rat or rabbit retinal membrane preparations (Enna and Snyder, 1976; Redburn et al., 1979; Redburn and Mitchell, 1981). Preferential and rapid GABA transport by the avid glial and neuronal uptake systems present in the rabbit retina (Ehinger, 1977), for which muscimol is a poor substrate, may be responsible for this apparent discrepancy, especially if there are transport sites close to the region of the synapse to 
reduce the local extracellular GABA concentration. If the efficacy of poorly transported muscimol can be potentiated by blocking the GABA transport system, as has been reported previously (Lodge et al., 1978), then the effect of the transport system on GABA levels must be proportionately much greater and probably has a pronounced influence on retinal functions.

It is surprising that the $B$ wave of the ERG should be enhanced by an inhibitory transmitter such as GABA, although this has been reported previously (Starr, 1975). The B-wave probably results from depolarizing bipolar cell-generated $\mathrm{K}^{+}$fluxes in the distal retina (Dick and Miller, 1978), which may be increased by GABA as shown for the $\mathrm{K}^{+}$efflux in neuronal cell cultures (Hosli et al., 1981). However, the inhibition of the $B$ wave by picrotoxin, a compound thought to act on the chloride ionophore (Ticku and Olsen, 1977), as opposed to the ineffeclive receptor-acting bicuculline, may indicate an effect on chloride-dependent depolarizing bipolar cells.

The effects of nipecotic acid may be interpreted in several different ways, but it seems unlikely that a direct action on the GABA receptor is responsible since the $\mathrm{IC}_{50}$ for nipecotic acid is greater than $1 \mathrm{~mm}$ in GABA binding studies (Krogsgaard-Larsen et al., 1978; Lester and Peck, 1979) and 5 mm nipecotic acid had no direct effect on crayfish stretch receptor neurons (Krause et al., 1981). However, nipecotic acid effectively blocks GABA transport and the gradual inhibition of light-evoked $\mathrm{ACh}$ release probably is due to the slow accumulation of extracellular GABA. This would be consistent with the GABA-mimetic action of nipecotic acid on the ERG. When nipecotic acid is removed, a rapid clearance of GABA should cause a prompt recovery as seen in these experiments. This again indicates the probable importance of the GABA uptake system and appears to be consistent with a tonic GABA release. However, this latter notion is complicated by the fact that nipecotic acid itself may cause GABA release by heteroexchange (Johnston et al., 1976a, b). We also note that nipecotic acid has some properties as a glycine receptor antagonist (Krogsgaard-Larsen et al., 1975); however, since blockade of inhibitory glycine input should lead to increased ACh release, as opposed to the slow decrease observed in these experiments, this further implies that the cholinergic neurons receive an inhibitory input from GABAergic, rather than glycinergic, cells.

Specificity of GABA antagonists. Receptor binding studies show that bicuculline, GABA, and muscimol will displace each other (Mohler and Okada, 1977; Andrews and Johnston, 1979) but not dihydropicrotoxinin (Olsen et al., 1978). This suggests that bicuculline binds to the GABA receptor, while picrotoxin acts at an independent site (Simmonds, 1980), such as the GABA-activated chloride ionophore (Ticku and Olsen, 1977). Although active at different sites, both compounds block the postsynaptic effects of GABA (Krnjevic, 1974; Johnston, 1978), and in conjunction with strychnine, they may be used effectively to differentiate between GABA and glycine input (Homma and Rovainen, 1978; Blume et al., 1981) but only at low concentrations. In the mud puppy retina, bicuculline and picrotoxin selectively antagonize GABA at $10^{-4} \mathrm{M}$ or less, while strychnine, at $10^{-5} \mathrm{M}$ or less blocks glycine but not GABA (Miller et al., 1981a). Similar results in the frog retina were reported by Mooney (1978) using concentrations of $10^{-5} \mathrm{gm} / \mathrm{ml}(20 \mu \mathrm{M}$ for $N$-methyl bicuculline and $30 \mu \mathrm{M}$ for strychnine), and since the concentrations used in these experiments are considerably lower than either of the above examples, the GABA/ glycine dichotomy should be clear.

The specificity of bicuculline and picrotoxin in our experiments also must be examined in light of reports describing multiple actions for these compounds. For instance, the effects of serotonin on both central and peripheral neurons can be blocked by picrotoxin but not bicuculline (Segal 1976; Simonds and DeGroat, 1980), although, in one report, both antagonists were partially effective (Mayer and Straughan, 1981). Bicuculline also can antagonize the effects of taurine (Curtis et al., 1971) and it has some anticholinesterase activity $(K i=65 \mu \mathrm{M})$ (Svenneby and Roberts, 1973; Miller and McLennan, 1974). However, neither of these factors is likely to contribute to our results since taurine apparently acts at strychnine-sensitive receptors in the retina (Bonaventure et al., 1974; Cunningham and Miller, 1980) and our experiments were performed routinely in eserinized Krebs solution. Finally, there remains the possibility that the excitatory effects of bicuculline and picrotoxin arise from some direct or "nonspecific" effects (Krnjevic, 1974; Collins and Hill, 1974), but these probably were due to the instability of bicuculline (Olsen et al., 1975) or high iontophoretic ejection rates. Using dissociated cell cultures of mouse neurons, Heyer et al. (1981) showed that bicuculline could prolong calcium-dependent action potentials and produce direct, nonsynaptic depolarizations at concentrations up to $200 \mu \mathrm{M}$. However, the threshold dose was approximately $5 \mu \mathrm{M}$ and these direct actions are not likely to be significant in our experiments.

In summary, we suggest that bicuculline and picrotoxin exert their effects on $\mathrm{ACh}$ release from the rabbit retina purely by the blockage of endogenous GABA. We come to this conclusion for the following reasons: (1) the amino acid antagonists were used at low concentrations, widely reported to be selective for GABA. (2) The picrotoxin/ bicuculline-evoked release of radioactivity was identificd as $\mathrm{ACh}$, whereas the $\mathrm{Ch}$ efflux was unchanged and no other metabolites were detected. (3) The picrotoxin/ bicuculline-evoked release was absolutely calcium dependent, indicating a neuronal origin for this component. (4) Muscimol, a potent GABA agonist, blocked the stimulating effects of bicuculline, indicating an action at GABA receptors. Picrotoxin was not blocked by muscimol, consistent with the idea that the picrotoxin acts at a different site independent from the GABA receptor. (5) Strychnine and TAG, a putative taurine antagonist (Yarbrough et al., 1981), had no effect on ACh release.

Evidence for the tonic release of GABA. The bicuculline/picrotoxin-evoked release of ACh strongly suggests a dark, tonic, or resting release of GABA, which is consistent with the slow effect of nipecotic acid. If hyperpolarizing bipolar cells are predominantly active in the dark (Miller, 1979), this tonic release may indicate that some GABA-releasing amacrine cells receive input from hyperpolarizing bipolar cells. A tonic release of GABA also has been suggested by Miller et al. (1981a, b) based on their intracellular recordings from the mud puppy retina. Since only GABA-sensitive neurons were affected, they 
ascribe the excitatory action of bicuculline/picrotoxin to a blockade of tonically released GABA, as opposed to nonspecific, direct excitation. They also noted that cells from the ON pathway were inhibited predominantly by GABA. This is consistent with the suggestion that many cholinergic amacrine cells receive ON input (Massey et al., 1981). Dopamine turnover and the activation of tyrosine hydroxylase also were enhanced by bicuculline and picrotoxin (Kamp and Morgan, 1981; Marshburn and Iuvone, 1981). Together, these observations suggest that the inner retina is under the continuous inhibitory influence of GABA.

Localization of GABA pathways. Although these experiments do not identify the site of GABA input, it is interesting to consider the possible synaptic arrangements. A pathway such as cholinergic amacrine cells feeding forward to GABAergic amacrine cells with a subsequent negative feedback may be ruled out since cholinergic antagonists do not change the resting release of ACh, nor do they alter the effects of GABA antagonists (Massey and Redburn, 1980). An intermediate amacrine cell between GABAergic and cholinergic amacrine cells also seems improbable because strychnine, dopamine, serotonin, and a large variety of peptides had no effect on ACh release (S. C. Massey and D. A. Redburn, unpublished observations; Cunningham and Neal, 1981), although, of course, a novel transmitter could be employed.

The two major synaptic alternatives appear to be direct inhibition of either the cholinergic amacrine cells or their presumed bipolar cell inputs. Amacrine and bipolar cells are inhibited directly by GABA in the mud puppy retina (Miller et al., 1981a, b) and electron microscopic analysis of immunocytochemically stained tissue revealed that GABAergic amacrine cells contact both cell types in rabbit (Brandon et al., 1980) and rat retinas (Vaughn et al., 1981). GABAergic amacrine cells of several morphological varieties are widespread throughout the inner plexiform layer of mammalian retinas (Berger et al., 1977; Brandon et al., 1979, 1980; Pourcho, 1980, 1981), and it seems probably that activation of either site by exogenously applied GABA would effectively reduce ACh release. A suggestion of direct GABA input may be gleaned from the location of muscimol binding sites which are widespread in the inner plexiform layer of chick retina but are maximal in sublaminas 2 and 4 (Yazulla and Brecha, 1981), coincident with the location of cholinergic terminals (Baughman and Bader, 1977). We also note that dopaminergic cells in the rat retina appear to receive a direct inhibitory GABA input (Marshburn and Iuvone, 1981). The paucity of GABAergic synapses upon ganglion cell dendrites in the rabbit retina (Brandon et al., 1980) raises the interesting possibility that the excitatory effects of picrotoxin on ganglion cells (Ariel and Daw, 1978) may be mediated, at least in part, by enhanced ACh release. However, these speculations may best be answered by some form of double label analysis.

\section{References}

Andrews, P. R., and G. A. R. Johnston (1979) GABA agonists and antagonists. Biochem. Pharmacol. 28: 2697-2702.

Ariel, M, and N. W. Daw (1978) Effect of acetylcholine drugs on receptive field properties of rabbit retinal ganglion cells. Soc. Neurosci. Abstr. 4: 619.

Arial, M., and N. W. Daw (1979) Effect of physostigmine on "ON-OFF" and "ON-center sustained" rabbit ganglion cells. Invest. Ophthalmol. Suppl. 18: 34.

Baughman, R. W., and C. R. Bader (1977) Biochemical characterization and cellular localization of the cholinergic system in the chicken retina. Brain Res. 138: 469-485.

Belgum, J. H., and J. S. McReynolds (1979) Synaptic transmission in the outer plexiform layer of the Necturus retina. Invest. Ophthalmol. Suppl. 18: 32.

Berger, S. J., M. L. McDaniel, J. G. Carter, and O. H. Lowry (1977) Distribution of four potential transmitter amino acids in monkey retina. J. Neurochem. 28: 159-163.

Blume, H. W., Q. J. Pittman, and L. P. Renaud (1981) Sensitivity of identified medial hypothalamic neurons to GABA, glycine and related amino acids: Influence of bicuculline, picrotoxin and strychnine on synaptic inhibition. Brain Res. 209: 145-158.

Bonaventure, N., N. Wioland, and P. Mandel (1974) Antagonists of the putative inhibitory transmitter effects of taurine and GABA in the retina. Brain Res. 80: 281-289.

Brandon, C., D. M. K. Lam, and J. -Y. Wu (1979) The $\gamma$ aminobutyric acid system in rabbit retina: Localization by immunocytochemistry and autoradiography. Proc. Natl. Acad. Sci. U. S. A. 76: 3557-3561.

Brandon, C., D. M. K. Lam, Y. Y. T. Su, and J. -Y. Wu (1980) Immunocytochemical localization of GABA neurons in the rabbit and frog retina. Brain Res. Bull. Suppl. 2 5: 21-29.

Collins, J. F. and R. G. Hill (1974) (+) and (-)-bicuculline methochloride as optical isomers of a GABA antagonist. Nature 249: 845-847.

Cunningham, R., and R. F. Miller (1980) Electrophysiological analysis of taurine and glycine action on neurons of the mudpuppy retina. I. Intracellular recording. Brain Res. 197: 123-138.

Cunningham, R. J., and M. J. Neal (1981) Effect of GABA agonists, glycine and neuropeptides on the release of acetylcholine (ACh) from the rabbit retina in vivo. Br. J. Pharmacol. 74: 879P.

Curtis, D. R., A. W. Duggan, D. Felix, G. A. R. Johnston, and H. McLennan (1971) Antagonism between bicuculline and GABA in the cat brain. Brain Res. 33: 57-73.

Daniels, M. P., and Z. Vogel (1980) Localization of $\alpha$-bungarotoxin binding sites in synapses of the developing chick retina. Brain Res. 201: 45-56.

DeFeudis, F. V. (1980) Binding studies with muscimol; relation to synaptic $\gamma$-aminobutyrate receptors. Neuroscience 5: 675688.

Dick, E., and R. F. Miller (1978) Light-evoked potassium activity in mudpuppy retina: Its relationship to the B-wave of the electroretinogram. Brain Res. 154: 388-394.

Ehinger, B. (1977) Glial and neuronal uptake of GABA, glutamic acid, glutamine and glutathione in the rabbit retina. Exp. Eye Res. 25: 221-234.

Ehinger, B., and B. Falck (1971) Autoradiography of some suspected neurotransmitter substances: GABA, glycine, glutamic acid, histamine, dopamine and L-DOPA. Brain Res. 113: 535-549.

Ehrlich, D., and I. G. Morgan (1980) Kainic acid destroys displaced amacrine cells in post-hatch chicken retina. Neurosci. Lett. 17: 43-48.

Enna, S. J., and S. H. Snyder (1976) Gamma-aminobutyric acid (GABA) receptor binding in mammalian retina. Brain Res. 115: 174-179.

Fonnum, F. (1969) Isolation of choline esters from aqueous solutions by extraction with sodium tetraphenylboron in organic solvents. Biochem. J. 113: 291-298.

Gerschenfeld, H. M., and M. Piccolino (1977) Muscarinic an- 
tagonists block cone to horizontal cell transmission in turtle retina. Nature 268: 257-259.

Graham, L. T., Jr. (1974) Comparative aspects of neurotransmitters in the retina. In The Eye. Vol 6: Comparative Physiology, H. Davson and L. T. Graham, Jr., eds., pp. 283-342, Academic Press, New York.

Hadhazy, P., and J. C. Szerb (1977) The effect of cholinergic drugs on ${ }^{3} \mathrm{H}$-acetylcholine release from slices of rat hippocampus, striatum and cortex. Brain Res. 123: 311-322.

Hayden, S. A., J. W. Mills, and R. H. Masland (1980) Acetylcholine synthesis by displaced amacrine cells. Science 210: 435-437.

Heyer, E. J., L. M. Nowak, and R. L. MacDonald (1981) Membrane depolarization and prolongation of calicum-dependent action potentials of mouse neurons in cell culture by two convulsants: Bicuculline and penicillin. Brain Res. 232: 41-56.

Homma, S., and C. M. Rovainen (1978) Conductance increases produced by glycine and $\gamma$-aminobutyric acid in lamprey interneurons. J. Physiol. (Lond.) 279: 231-252.

Hosli, L., E. Hosli, P. F. Andres, and H. Landolt (1981) Evidence that the depolarization of glial cells by inhibitory amino acids is caused by an efflux of $\mathrm{K}^{+}$from neurons. Exp. Brain Res. 42: 43-48.

Hughes, A., and D. I. Vaney (1980) Coronate cells: Displaced amacrines of the rabbit retina. J. Comp. Neurol. 189: 169189.

Johnson, D. A., and G. Pilar (1980) The release of acetylcholine from post-ganglion cell bodies in response to depolarization. J. Physiol. (Lond.) 299: 605-619.

Johnston, G. A. R. (1978) Neuropharmacology of amino acid inhibitory transmitters. Annu. Rev. Pharmacol. Toxicol. 18: 269-289.

Johnston, G. A. R., P. Krogsgaard-Larsen, A. L. Stephanson, and $B$. Twitchin (1976a) Inhibition of the uptake of GABA and related amino acids in rat brain slices by the optical isomers of nipecotic acid. J. Neurochem. 26: 1029-1032.

Johnston, G. A. R., A. L. Stephanson, and B. Twitchin (1976b) Uptake and release of nipecotic acid by rat brain slices. $J$. Neurochem. 26: 83-87.

Johnston, G. A. R., S. M. E. Kennedy, and D. Lodge. (1978) Muscimol uptake, release and binding in rat brain slices. J. Neurochem. 31: 1519-1523.

Kamp, C. W., and W. W. Morgan (1981) GABA antagonists enhance dopamine turnover in the rat retina. Eur. J. Pharmacol. 69: 273-279.

Kaneko, A., and II. Shimazaki (1976) Synaptic transmission from photoreceptors to the second-order neurons in the carp retina. In Neural Principles in Vision, F. Zettler and $\mathrm{R}$. Weiler, eds., pp. 143-157, Springer-Verlag, Berlin.

Krause, D. N., K. Ikeda, and E. Roberts (1981) Dose-conductance relationships for GABA agonists and the effect of uptake inhibitors in crayfish stretch receptor neurons. Brain Res. 225: 319-332.

Krnjevic, K. (1974) Chemical nature of synaptic transmission in vertebrates. Physiol. Rev. 54: 418-540.

Krogsgaard-Larsen, P., G. A. R. Johnston, D. R. Curtis, C. J. A. Game, and R. M. McCulloch (1975) Structure and biological activity of a series of conformationally restricted analogues of GABA. J. Neurochem. 25: 803-809.

Krogsgaard-Larsen, P., G. A. R. Johnston, D. Lodge, and D. R. Curtis (1977) A new class of GABA agonist. Nature 268: 5355.

Krogsgaard-Larsen, P., T. Honone, and K. Thyssen (1978) GABA receptor agonists: Design and structure-activity studies. In GABA-Neurotransmitters, P. Krogsgaard-Larsen, J. Scheel-Kruger, and H. Kofod, eds., pp. 201-216, Academic Press, New York.
Lam, D. M. K. (1972) Biosynthesis of acetylcholine in turtle photoreceptors. Proc. Natl. Acad. Sci. U. S. A. 69: 1987-1991.

Lam, D. M. K., E. M. Lasater, and K. -I. Naka (1978) $\gamma$ Aminobutyric acid: A neurotransmitter for cone horizontal cells of the catfish retina. Proc. Natl. Acad. Sci. U. S. A. 75: $6310-6313$

Lam, D. M. K., Y. Y. T. Su, L. Swain, R. E. Marc, C. Brandon, and J. -Y. Wu (1979) Immunocytochemical localizatin of Lglutamic acid decarboxylase in the goldfish retina. Nature 278: 565-567.

Lam, D. M. K., S. -C. Fung, and Y. -C. Kong (1980) Postnatal development of GABA-ergic neurons in the rabbit retina. J. Comp. Neurol. 193: 89-102.

Lehman, J., and H. C. Fibiger (1979) Acetylcholinesterase and the cholinergic neuron. Life Sci. 25: 1939-1947.

Lester, B. R., and E. J. Peck, Jr. (1979) Kinetic and pharmacologic characterization of gamma-aminobutyric acid receptive sites from mammalian brain. Brain Res. 161: 79-97.

Lodge, D., D. R. Curtis, and G. A. R. Johnston (1978) Does uptake limit the action of GABA agonists in vivo? Experiments with muscimol, isoguvacine and THIP in cat spinal cord. J. Neurochem. 31: 1525-1528.

Marc, R. E., W. K. Stell, D. Bok, and D. M. K. Lam (1978) GABA-ergic pathways in the goldfish retina. J. Comp. Neurol. 182: 221-246.

Marshburn, P. B., and M. Iuvone (1981) The role of GABA in the regulation of the dopamine/tyrosine hydroxylase-containing neurons of the rat retina. Brain Res. 214: 335-347.

Masland, R. H., and A. Ames, III (1976) Responses to acetylcholine of ganglion cells in an isolated mammalian retina. J. Neurophysiol. 39: 1220-1235.

Masland, R. H., and C. J. Livingstone (1976) Effect of stimulation with light on synthesis and release of acetylcholine by an isolated mammalian retina. J. Neurophysiol. 3.9: 12101219.

Masland, R. H., and J. W. Mills (1979) Autoradiographic identification of acetylcholine in the rabbit retina. J. Cell Biol. 83: 159-178.

Massey, S. C., and M. J. Neal (1979) The light-evoked release of acetylcholine from the rabbit retina in vivo and its inhibition by $\gamma$-aminobutyric acid. J. Neurochem. 32: 1327-1329.

Massey, S. C., and D. A. Redburn (1980) GABA inhibition of light-evoked $\mathrm{ACh}$ release. Invest. Ophthalmol. Suppl. 19: 283.

Massey, S. C., M. L. J. Crawford, and D. A. Redburn (1981) Many cholinergic amacrine cells in rabbit retina receive $O N$ input. Invest. Ophthalmol. Suppl. 20: 44.

Mayer, M. L. and D. W. Straughan (1981) Effects of 5-hydroxytryptamine on central neurons antagonized by bicuculline and picrotoxin. Neuropharmacology 20: 347-350.

Miller, J. J., and H. McLennan (1974) The action of bicuculline upon acetylcholine-induced excitations of central neurones. Neuropharmacology 13: 785-787.

Miller, R. F. (1979) The neuronal basis of ganglion cell receptive field organization and the physiology of amacrine cells. In The Neurosciences: Fourth Study Program, F. O. Schmitt and F. G. Worden, eds. pp. 227-245, MIT Press, Cambridge, MA.

Miller, R. F., T. E. Frumkes, M. Slaughter, and R. F. Dacheux (1981a) Physiological and pharmacological basis of GABA and glycine action on neurons of mudpuppy retina. I. Receptors, horizontal cells, bipolars and G-cells. J. Neurophysiol. 45: 743-763.

Miller, R. F., T. E. Frumkes, M. Slaughter, and R. F. Dacheux (1981b) Physiological and pharmacological basis of GABA and glycine action on neurons of mudpuppy retina. II. Amacrine and Ganglion cells. J. Neurophysiol. 45: 764-782.

Mohler, H., and T. Okada (1977) GABA receptor binding with 
${ }^{3} \mathrm{H}(+)$ bicuculline-methiodide in rat CNS. Nature 267: 6567.

Mooney, R. D. (1978) GABA-mediated control of transient signals in the inner retina. Brain Res. 165: 97-115.

Murakami, M., K. Ohtsu, and T. Ohtsuka (1972) Effects of chemicals on receptors and horizontal cells in the retina. $J$. Physiol. (Lond.) 227: 899-913.

Neal, M. J., and S. C. Massey (1980) The release of acetylcholine and amino acids from the rabbit in vivo. Neurochem. Int. 1: 191-208.

Negishi, K., and B. D. Drujan (1979) Similarities in effects of acetylcholine and dopamine on horizontal cells in the fish retina. J. Neurosci. Res. 4: 335-349.

Negishi, K., S. Kato, T. Teranishi, and M. Lauter (1978) An electrophysiological study on the cholinergic system in the carp retina. Brain Res. 148: 85-93.

Nichols, C. W., and G. B. Koelle (1968) Comparison of the localization of acetylcholinesterase and non-specific cholinesterase activities in mammalian and avian retinas. J. Comp. Neurol. 133: 1-16.

Nichols, C. W., J. Hewitt, and A. M. Laties (1972) Localization of acetylcholinesterase in the teleost retina. J. Histochem. Cytochem. 20: 130-136.

Niemeyer, G. (1978) Cholinergic antagonists fail to block Spotentials in the cat retina. Invest. Ophthalmol. Suppl. 17: 285-286.

Olsen, R. W., M. Ban, T. Miller, and G. A. R. Johnston (1975) Chemical instability of the GABA antagonist bicuculline under physiological conditions. Brain Res. 98: 383-387.

Olsen, R. W., D. Greenless, P. Van Ness, and M. K. Ticku (1978) Studies on the gamma-aminobutyric acid receptor/ ionophore proteins in mammalian brain. In Amino Acids as Chemical Transmitters, F. Fonnum, eds., pp. 467-486, Plenum Press, New York.

Pande, S. V. (1976) Liquid scintillation counting of aqueous samples using Triton containing scintillants. Anal. Biochem. 74: $25-34$

Pourcho, R. G. (1979) Localization of cholinergic synapses in mammalian retina with peroxidase-conjugated $\alpha$-bungarotoxin. Vision Res. 19: 287-292.

Pourcho, R. G. (1980) Uptake of $\left[{ }^{3} \mathrm{H}\right]$ glycine and $\left[{ }^{3} \mathrm{H}\right] \mathrm{GABA}$ by amacrine cells in the cat retina. Brain Res. 198: 333-346.

Pourcho, R. G. (1981) Autoradiographic localization of $\left[{ }^{3} \mathrm{H}\right]$ muscimol in the cat retina. Brain Res. 215: 187-199.

Reale, E., L. Luciano, and M. Spitznas (1971) The fine structural localization of acetylcholinesterase activity in the retina and optic nerve of rabbits. J. Histochem. Cytochem. 19: 85-96.

Redburn, D. A., and C. K. Mitchell (1981) ${ }^{3} \mathrm{H}$-Muscimol binding in synaptosomal fractions from bovine and developing rabbit retinas. J. Neurosci. Res., 6: 487-495.

Redburn, D. A., C. B. Kyles, and J. Ferkany (1979) Subcellular distribution of GABA receptors in bovine retina. Exp. Eye Res. 28: 525-532.

Ross, C. D., and D. B. McDougall, Jr. (1976) The distribution of choline acetyltransferase activity in vertebrate retina. J. Neurochem. 26: 521-526.

Sarthy, P. V., and D. M. K. Lam (1978) Biochemical studies of isolated glial (Muller) cells from the turtle retina. J. Cell Biol. 78: 675-684.

Segal, M. (1976) 5-HT antagonists in rat hippocampus. Brain Res. 103: 161-166.
Shea, P. A., and M. H. Aprison (1973) An enzymatic method for measuring picomole quantities of acetylcholine and choline in CNS tissue. Anal. Biochem. 56: 165-177.

Silver, A. (1974) The Biology of Cholinesterase, Elsevier/ North-Holland, Inc., New York.

Simmonds, M. A. (1980) Evidence that bicuculline and picrotoxin act at separate sites to antagonise $\gamma$-aminobutyric acid in rat cuneate nucleus. Neuropharmacology 19: 39-45.

Simonds, W. I., and W. C. DeGroat (1980) Antagonism by picrotoxin of 5-hydroxytryptamine-induced excitation of primary afferent neurons. Brain Res. 192: 592-597.

Starr, M. S. (1975) The effects of various amino acids, dopamine and some convulsants on the electroretinogram of the rabbit. Exp. Eye Res. 21: 79-87.

Sugiyama, H., M. P. Daniels, and M. Nirenberg (1977) Muscarinic acetylcholine receptors of the developing retina. Proc. Natl. Acad. Sci. U. S. A. 74: 5524-5528.

Svenneby, E., and E. Roberts (1973) Bicuculline and $N$-methylbicuculline-competitive inhibitors of brain acetylcholinesterase. J. Neurochem. 21: 1025-1026.

Ticku, M. K., and R. W. Olsen (1977) $\gamma$-Aminobutyric acidstimulated chloride permeability in crayfish muscle. Biochem. Biophys. Acta 464: 519-529.

Vaney, D. I. (1980) A quantitative comparison between the ganglion cell populations and axonal outflows of the visual streak and periphery of the rabbit retina. J. Comp. Neurol. 189: 215-233.

Vancy, D. I., L. Peichl, and B. B. Boycott (1981) Matching populations of amacrine cells in the inner nuclear and ganglion cell layers of the rabbit retina. J. Comp. Neurol. 199: 373-391.

Vaughn, J. E., E. V. Famiglietti, Jr., R. P. Barber, K. Saioto, E. Roberts, and C. E. Ribak (1981) GABAergic amacrine cells in rat retina: Immunocytochemical identification and synaptic connectivity. J. Comp. Neurol, 197: 113-127.

Vivas, I. M., and B. D. Drujan (1980) Certain aspects of acetylcholine metabolism in teleost retina. Neurochem. Res. 5: 817829 .

Vogel, Z., and Nirenberg M. (1976) Localization of acetylcholine receptors during synaptogenesis in retina. Proc. Natl. Acad. Sci. U. S. A. 73: 1806-1810.

Vogel, Z., G. J. Maloney, A. Ling, and M. P. Daniels (1977) Identification of synaptic acetylcholine receptor sites in retina with peroxidase-labeled $\alpha$-bungarotoxin. Proc. Natl. Acad. Sci. U. S. A. 74: 3268-3272.

Wu, S. M. and J. E. Dowling (1978) L-Aspartate: Evidence for a role in cone photoreceptor synaptic transmitter in the carp retina. Proc. Natl. Acad. Sci. U. S. A. 75: 5205-5209.

Yarbrough, G. G., D. K. Singh, and D. A. Taylor (1981) Neuropharmacological characterization of a taurine antagonist. J. Pharmacol. Exp. Ther. 219: 604-612.

Yazulla, S., and N. Brecha (1980) Binding and uptake of the GABA analogue, ${ }^{3} \mathrm{H}$-muscimol, in the retinas of goldfish and chicken. Invest. Ophthalmol. 19: 1415-1426.

Yazulla, S., and N. Brecha (1981) Localized binding of $\left[{ }^{3} \mathrm{H}\right]$. muscimol to synapses in chicken retina. Proc. Natl. Acad. Sci. U. S. A. 78: 643-647.

Zucker, C., and S. Yazulla (1982) Localization of synaptic and nonsynaptic nicotinic-acetylcholine receptors in the goldfish retina. J. Comp. Neurol. 204: 188-195. 